\title{
Influence of water temperature and oxygenation on the aerobic metabolic scope of Atlantic cod (Gadus morhua)
}

\author{
G. Claireaux ${ }^{*}$, a , D. M. Webber ${ }^{b}$, J. -P. Lagardère ${ }^{a}$ and S. R. Kerr ${ }^{b}$
}

a Centre de Recherche en Ecologie Marine et Aquaculture, CREMA-L'Houmeau, CNRS-IFREMER, BP 5, Place du seminaire, L'Houmeau, 17137 France

b Biology Department, Dalhousie University, Halifax NS, Canada B3H 4J1

*: Corresponding author : guy.claireaux@ifremer.fr

\begin{abstract}
:
Environmental influences (temperature and oxygenation) on cod metabolism and their impact on the ecology of this species were investigated. Limiting oxygen concentration curves $\left(\mathrm{O}_{2}\right.$ level ranging between 15 and $100 \%$ air saturation) were established at 2,5 and $10^{\circ} \mathrm{C}$. The standard metabolic rate (SMR), the maximum metabolic rate and the metabolic scope were then modelled as functions of temperature and/or oxygen saturation. The mean SMR at 2,5 and $10^{\circ} \mathrm{C}$ were $19.8 \pm 4.9,30.8 \pm 6.1$ and $54.3 \pm 4.1 \mathrm{mg} \mathrm{O}_{2} \mathrm{~h}^{-1} \mathrm{~kg}^{-1}$, respectively. Between 2 and $5^{\circ} \mathrm{C}$, the active metabolic rate of cod almost doubled from 65 to $120 \mathrm{mg} \mathrm{O}_{2} \mathrm{~h}^{-1} \mathrm{~kg}^{-1}$, to reach $177 \mathrm{mg} \mathrm{O}_{2} \mathrm{~h}^{-1} \mathrm{~kg}^{-1}$ at $10^{\circ} \mathrm{C}$. In terms of metabolic scope (MS), the temperature rise from 2 to $5^{\circ} \mathrm{C}$ resulted in a two-fold increase from 45 to $89 \mathrm{mg}$ $\mathrm{O}_{2} \mathrm{~h}^{-1} \mathrm{~kg}^{-1}$, with MS reaching $123 \mathrm{mg} \mathrm{O}_{2} \mathrm{~h}^{-1} \mathrm{~kg}^{-1}$ at $10^{\circ} \mathrm{C}$. Our proposed model describing the impact of temperature and oxygen level provides new insight into the energetic interactions which govern the relationship between Atlantic cod and its environment. We re-examined published experimental and field studies from the angle of the regulation of metabolic power. We suggest that, when faced with heterogeneous or unstable hydrological conditions, cod tend to behaviourally maximise their metabolic scope. Through this adaptive response, fish reduce energy budgeting conflicts and presumably increase the probability of routinely operating away from lethal boundaries.
\end{abstract}

Keywords: Atlantic cod; metabolism; physiological ecology; temperature; oxygen 


\section{Introduction}

Over the past decade, the crisis experienced by the Northwest Atlantic cod fisheries has created a general consensus that more emphasis be placed on the link between biology oceanography and fisheries science (Brander, 1996; Rose, 1997). A lot of information has already been collected in a great diversity of research areas such as life history, physiology, habitat, interspecific interaction, etc. However, these pieces of information still largely remain to be assembled in an interpretable and operational picture. For review, see the special issues of ICES Mar. Sci. Symp. 198, 1994 and of Can. J. Fish. Aquat. Sci. 54 Suppl.1, 1997. Despite this lack of integration, the data set currently at hand assuredly illustrate the complexity of the functional relationships between cod biology and marine ecosystem dynamics, a complexity that definitely cannot be grasped through solely a mathematical or statistical approach.

Physical and chemical features of fish habitat have been classified as lethal, controlling, limitting or directive, depending on the nature of their influence on fish physiology or behaviour (Fry, 1971; see also Kerr, 1990). Through the constraints they exert, environmental factors contribute to determine the size of fish actual or realised niches, as well to set the bioenergetical conditions governing their use (Magnuson and Destasio, 1996). In this regard, the coercion exerted by ambient temperature and oxygenation on fish metabolic power output is of particular importance. While temperature is a powerful controlling factor of fish metabolic demand, water oxygenation level sets the upper limit to metabolism and therefore delineates the energetic framework (metabolic scope) within which aerobic metabolism may occur (Neill et al., 1994; Claireaux and Lagardère, 1999). 
One way to analyse the environmental constraints and their consequences on fish energetics is to actually measure metabolic expenditure in free ranging animals. In spite of the difficulties inherent in this approach, successful attempts have been made, in particular via the telemetry of physiological correlates to metabolism. However, if information can be obtained from in situ estimations of routine energy expenditure, the full explanatory power allowed by this approach can be achieved only if the metabolic scope of the animal is simultaneously taken into consideration. In terms of energy, the double challenge facing an animal trying to survive is indeed to achieve the power output necessary to live in its selected niche while operating as low as possible from its maximum power rating or active aerobic metabolic rate (Priede, 1977 and 1985).

In this context, the aim of the present investigation was to contribute to the understanding of the ecological consequences of the environmental influences on cod metabolism. Limiting oxygen concentration curves were established at 2,5 and $10^{\circ} \mathrm{C}$. The maximum metabolic rate and the metabolic scope were modelled as functions of temperature and oxygen saturation according to the method described in Claireaux and Lagardère (1999). We then compared experimental and modelling results to published data. Finally, via the reexamination published experimental results or field observations we verified to what extent cod distribution and migration patterns involve the necessity of optimising aerobic metabolic capacity. 


\section{Materials and methods}

\subsection{Fish}

Atlantic cod (Gadus morhua) of both sexes and weighing 950 to 1850 g were captured by trawling on the Scotian Shelf (NAFO division 4W), and transported to Dalhousie University (Halifax, Canada) where they were kept for more than a year in $6000 \mathrm{l}$ circular tanks supplied with temperature controlled fresh seawater between 9 and $10{ }^{\circ} \mathrm{C}$. During that period, fish were fed a mixed diet of chopped squid, herring and mackerel once or twice a week. An artificial lighting regime matched the natural photoperiod cycle. At least 3 weeks before experiments started, 36 fish were divided among 3 tanks $\left(1.2 \mathrm{~m}^{3}\right)$ where they were acclimated to the experimental temperatures, i.e. 10,5 and $2{ }^{\circ} \mathrm{C}$. Feeding was discontinued $24 \mathrm{~h}$ before any manipulation of the animals and 3 to 5 days ahead of their transfer into the respirometer.

\subsection{Experimental protocol}

At each experimental temperature $\left(10,5\right.$ and $\left.2{ }^{\circ} \mathrm{C}\right)$, three groups of 3 individuals each were tested. The 3 fish that made up each experimental groups were selected so that the group total mass was approximately $3 \mathrm{~kg}$. Groups mean mass was $3.2 \pm 0.4 \mathrm{~kg}$. Following temperature acclimation, experimental groups were successively submitted to the following protocol. Fish were anaesthetised in a solution of ethyl-m-aminobenzoate (MS-222), weighed and introduced in a 2121 respirometer where they remained for a 4-5 day period. Two experimental procedures were then followed. During the first 3 to 4 days, fish were left undisturbed and their routine metabolic rate (RMR) was measured automatically at hourly 
interval. On the last day, fish were submitted to a stepwise decreases in ambient oxygenation (decrementing by $20 \mathrm{mmHg}$, from saturation down to $20 \mathrm{mmHg}$ ). At each $\mathrm{O}_{2}$ level, the pump controlling the sea water supply to the respirometer was shut off and water $\mathrm{Po}_{2}$ was continuously recorded for the next 15 minutes. The measuring chamber was then flushed with hypoxic sea water until the next oxygen step was reached (approximately 15 min, water flow $\left.=8 \mathrm{l} \cdot \mathrm{min}^{-1}\right)$. Following the last measurement $(15-20 \mathrm{mmHg})$, water oxygenation was brought back to $100 \%$ saturation.

Routine metabolic rates (RMR) were determined on spontaneously active groups of cod. Standard or resting metabolic rates (SMR) were estimated using the minimal RMR measured during the night when fish tended to remain motionless on the bottom of the respirometer and where interaction between individuals is minimal. To determine active metabolic rate (AMR) experimental groups were forced to swim until exhaustion prior to hypoxia. Moreover, some experimental groups (1-2 groups per temperature) were fed ad libitum prior to chasing. These different protocols provided several levels of activity thus contributing to the accuracy of our model.

The experimental set up used here was similar to the one described in Claireaux and Lagardère (1999). A computer controlled temperature-relay system maintained water temperature in the measuring chamber within $\pm 0.1^{\circ} \mathrm{C}$ of fish acclimation temperature. Oxygen partial pressure $\left(\mathrm{Po}_{2}\right)$ was measured using a Radiometer 5046 electrode regulated at the experimental temperature. The oxygen electrode was interfaced to an oxygen meter (Cameron Instrument) connected to a 'user designed' computerised data acquisition system. The oxygen probe was calibrated daily. Fish oxygen consumption $\left(\mathrm{MO}_{2}\right.$ in $\left.\mathrm{mgO}_{2} \cdot \mathrm{kg}^{-1} \cdot \mathrm{h}^{-1}\right)$ was calculated using the following formula: 
$\mathrm{MO}_{2}=\Delta \mathrm{Po}_{2} \cdot \mathrm{V} \cdot \alpha \cdot \mathrm{M}^{-1} \cdot \Delta \mathrm{t}^{-1}$

where $\Delta \mathrm{Po}_{2}$ is the change in water partial pressure of $\mathrm{O}_{2}(\mathrm{mmHg}), \Delta \mathrm{t}$ is the elapsed time $(\mathrm{h})$, $\mathrm{V}$ is the volume of the respirometer minus the volume of the fish (l), $\mathrm{M}$ is the total mass of the animals $(\mathrm{kg})$, and $\alpha$ is the $\mathrm{O}_{2}$ solubility coefficient at the experimental temperature (Boutilier et al., 1984).

Calculated $\mathrm{MO}_{2}$ were standardized to a $1 \mathrm{~kg}$ animal using a weight exponent of 0.82 (Edwards et al., 1972). Background $\mathrm{MO}_{2}$ was routinely measured at each temperature and substracted from fish oxygen consumption.

\subsection{Data processing}

Throughout the manuscript, data are presented as mean \pm SE. Water oxygenation values were expressed as percent of saturation $\left(\mathrm{So}_{2}\right)$. The modelling procedures were conducted as described in Claireaux and Lagardère (1999). Briefly, at each experimental temperature LOC-curves were eye-fitted to our oxygen consumption data-set. Limiting oxygen concentration curves (LOC-curves) describe the relationship between maximal aerobic performance $\left(\mathrm{MO}_{2 \max }\right)$ and ambient oxygenation. These LOC-curves were modelled using the following equation:

$\mathrm{MO}_{2 \max }=\mathrm{Y}_{1}\left(1-\mathrm{e}^{\left(\alpha_{1} \mathrm{So}_{2}+\beta_{1}\right)}\right)$,

where $\mathrm{So}_{2}$ is the ambient oxygen saturation, $\mathrm{Y}_{1}$ the asymptote, $\alpha_{1}$ and $\beta_{1}$ are two constants. 
Values of $\mathrm{Y}_{1}$ determined at each temperature were then modelled as a function of temperature using the formula below:

$Y_{1}=\alpha_{2} T^{\left(\beta_{2} T+\delta_{2}\right)}+\varepsilon_{2}$

where $\mathrm{T}$ is the temperature and $\alpha_{2}, \beta_{2}, \delta_{2}$ and $\varepsilon_{2}$ are constants.

The values of $\alpha_{1}$ and $\beta_{1}$ showed no correlation with temperature and were thus substituted with their averaged value ( $\alpha_{\mathrm{m}}$ and $\beta_{\mathrm{m}}$ ), while $\mathrm{Y}_{1}$ of equation 1 was substituted with equation 2. Equation 1 then became

$\mathrm{MO}_{2 \max }=\left(\left(\alpha_{2} \mathrm{~T}^{\left(\beta_{2} \mathrm{~T}+\delta_{2}\right)}+\varepsilon_{2}\right)\left(1-\mathrm{e}^{\left(\alpha_{\mathrm{m}} \mathrm{So}_{2}+\beta_{\mathrm{m}}\right)}\right)\right)$.

Standard metabolic rate was modelled as a function of temperature using the following formula:

$\operatorname{SMR}=Y_{3}\left(1-e^{\left(\alpha_{3} \mathrm{~T}^{\beta 3}\right)}\right)$

where $\mathrm{T}$ is temperature, $\mathrm{Y}_{3}$ the asymptote, $\alpha_{3}$ and $\beta_{3}$ two constants.

Finally, fish metabolic scope was modelled as a function of ambient temperature and oxygen saturation using the following equations:

$\mathrm{MS}=\mathrm{MO}_{2 \max }-\mathrm{SMR}$ 
i.e.,

$M S=\left(\left(\alpha_{2} T^{\left(\beta_{2} \mathrm{~T}+\delta_{2}\right)}+\varepsilon_{2}\right)\left(1-\mathrm{e}^{\left(\alpha_{\mathrm{m}} \mathrm{So}_{2}+\beta_{\mathrm{m}}\right)}\right)\right)-\left(\mathrm{Y}_{3}\left(1-\mathrm{e}^{\left(\alpha_{3} \mathrm{~T}^{\beta_{3}}\right)}\right)\right)$

\section{Results}

\subsection{Standard metabolic rate}

The mean standard metabolic rates at 2, 5 and $10{ }^{\circ} \mathrm{C}$ were $19.8 \pm 4.9,30.8 \pm 6.1$ and $54.3 \pm$

$4.1 \mathrm{mgO}_{2} \cdot \mathrm{h}^{-1} \cdot \mathrm{kg}^{-1}$ respectively (shaded area on Fig.1). Using equation 4, the relationship between SMR and temperature was modelled as:

$\operatorname{SMR}=80.1\left(1-\mathrm{e}^{\left(-0.185 \mathrm{~T}^{0.79}\right)}\right), \mathrm{r}^{2}=0.973$

where $\mathrm{T}$ is temperature (Fig.2).

\subsection{Limiting oxygen concentration curves}

The values of the various constants determined by modelling the LOC-curves (equation 1) are given in Table 1 . The asymptote of each LOC-curve $\left(\mathrm{Y}_{1}\right)$ corresponds to cod active metabolic rate (AMR) since it is the largest aerobic energy expenditure in normoxia. During hypoxia, decrease in ambient oxygen saturation below saturation resulted in a decline in cod metabolic capacity as the maximum oxygen consumption $\left(\mathrm{MO}_{2 \max }\right)$ progressively deviated from AMR, down the LOC-curve (Fig.1). Eventually $\mathrm{MO}_{2 \max }$ reached SMR at 
approximately $15-20 \%$ air saturation, therefore identifying the critical oxygen saturation ( $\left.\mathrm{S}_{\text {crit }}\right)$. At any temperature, the impact of ambient oxygenation on fish aerobic metabolic scope (MS) is illustrated by the shape of the area contained between the LOC-curve and SMR (Fig. 1).

As temperature of acclimation rose from 2 to $10^{\circ} \mathrm{C}$, we observed an increase in cod metabolic performance. Between 2 and $5{ }^{\circ} \mathrm{C}$ AMR almost doubled from 65 to $120 \mathrm{mgO}_{2} \cdot \mathrm{h}^{-}$ ${ }^{1} \cdot \mathrm{kg}^{-1}$, and finally reach $177 \mathrm{mgO}_{2} \cdot \mathrm{h}^{-1} \cdot \mathrm{kg}^{-1}$ when temperature increased to $10^{\circ} \mathrm{C}$ (Table 1 ). In terms of metabolic scope (MS), the temperature increase from 2 to $5{ }^{\circ} \mathrm{C}$ resulted in a 2 fold increase, from 45 to $89 \mathrm{mgO}_{2} \cdot \mathrm{h}^{-1} \cdot \mathrm{kg}^{-1}$, with MS reaching $123 \mathrm{mgO}_{2} \cdot \mathrm{h}^{-1} \cdot \mathrm{kg}^{-1}$ at $10{ }^{\circ} \mathrm{C}$. Using equation 2, the relationship between AMR and temperature (Fig. 2) was modelled as:

$\mathrm{Y}_{1}=17.29 \mathrm{~T}^{(-0.015 \mathrm{~T}+1.062)}+30.01, \mathrm{r}^{2}=0.983$

where $\mathrm{T}$ is temperature.

Based on equation $1, \mathrm{MO}_{2 \max }$ was modelled as a function of temperature and oxygenation level (Fig. 3a):

$\mathrm{MO}_{2 \max }=\left(17.29 \mathrm{~T}^{(-0.015 \mathrm{~T}+1.062)}+30.01\right)\left(1-\mathrm{e}^{\left(-0.035 \mathrm{So}_{2}+0.34\right)}\right)$.

where $\mathrm{T}$ is temperature, $\mathrm{So}_{2}$ ambient oxygen saturation and -0.035 and 0.34 the averaged $\alpha_{1}$ and $\beta_{1}$ respectively (Table1). 
Finally, metabolic scope was expressed as a function of temperature and oxygen using the following equation (equation 9 - equation 7; Fig. 3b):

$$
\text { MS }=\left(17.29 \mathrm{~T}^{(-0.015 \mathrm{~T}+1.062)}+30.01\right)\left(1-\mathrm{e}^{\left(-0.035 \mathrm{So}_{2}+0.34\right)}\right)-80.1\left(1-\mathrm{e}^{\left(-0.185 \mathrm{~T}^{0.79}\right)}\right)
$$

\section{Discussion}

Only experimental data measured in the current work were incorporated in the modeling procedure. Yet, a comparison of that model with numerous data available in the literature showed satisfactory agreement (Fig.2) and confirm the robust nature of our experimental and modeling approach (Claireaux and Lagardère, 1999). This correspondence particularly strengthened the view by others that 'mass respirometry' allows the determination of standard metabolic rate in fish (see also Saunders, 1963; Hop and Graham, 1995; Claireaux and Lagardère, 1999).

The influence of temperature on SMR was modeled using an asymptotic equation, althought a linear or exponential regression would have yielded higher $r^{2}$. The reason for us selecting such a model stemmed from the observation that when the whole set of published data was considered, an asymptotic equation then gave the best fit over the temperature range covered (Fig.2). This finding corroborates the view by Jobling (1993) that standard metabolic rate does not necessarily increase exponentially with increasing temperature. See also Beamish (1964), Evans (1990) Claireaux and Lagardère (1999). 
Modeling the impact of water oxygen content on cod aerobic metabolic capacity (Fig.1) sheds a new light on the energetic constraints imposed by oxygen as a directive factor (Fry, 1971). An attempt to use metabolic scope to analyze the functional relationship between fish distribution and the physical structure of the water column was made by Schurmann et al. (1998). In a mesocosm experiment these authors showed that free swimming European sea bass (Dicentrarchus labrax) spontaneously avoided water layers having an oxygen saturation less than $45 \%$. They described this oxygen saturation level as $S_{\text {avoid. }}$ These authors then calculated that fish exposed to $45 \%$ air-saturated water still had at their disposal about half of the metabolic scope measured in normoxia. They proposed that the range between $\mathrm{S}_{\text {avoid }}$ (MS $=50 \%)$ and the critical oxygen saturation $\left(\mathrm{S}_{\text {crit }} ; \mathrm{MS}=0\right)$ corresponds to some sort of safety margin within which ambient oxygenation progressively becomes a potent directive factor. In that range, vital activities are still sustained but energy allocation to secondary functions such as locomotion, digestion or reproduction are gradually lessened to fit within the animal's dwindling metabolic scope. The present investigation suggests that these observations also apply to Atlantic cod. Using a 11m deep, $125 \mathrm{~m}^{3}$, tower tank, Claireaux et al. (1995b) showed that free swimming cod confronted with a stratified water column avoided the bottom layer they ordinarily occupied when the oxygen saturation was reduced below 40-45 \%. Using equation 10 it can be calculated that the point beyond which environmental oxygen influences cod distribution also corresponds with the $50 \%$ metabolic scope threshold. Studies in nature also showed that water oxygenation level is related to the observed limits of the distribution of cod in the Gulf of St Lawrence, (Canada). D’Amours (1993) reported that cod were not found in waters having an oxygen concentrations lower than 3.4 mg. $\mathrm{l}^{-1}$ (temperature between 2 and $4{ }^{\circ} \mathrm{C}$ ). This prominent influence of ambient oxygenation on cod distribution range was also described in the Baltic Sea by Tomkiewicz et al. (1997). Furthermore, Schurmann and 
Steffensen (1994) experimentally determined that the incipient oxygen-dependent activity levels of cod were 40 and $52 \%$ air saturation at 5 and $10{ }^{\circ} \mathrm{C}$ respectively.

During the course of our experiment, we observed several instances when metabolic power budgets conflicted with restricted metabolic capacity On some occasions, animals in the respirometer were fed with chunks of herring and mackerel only a few hours before hypoxia was induced. As digestion and assimilation proceeded, their oxygen demand rose to the AMR level because of the increased metabolism associated with the apparent specific dynamic action. As $\mathrm{So}_{2}$ was then gradually reduced, fish $\mathrm{MO}_{2}$ followed the entire LOC-curve until the vicinity of $S_{\text {crit }}$. At this point, scope for activity being almost nil, all of the fish present in the measuring chamber simultaneously regurgitated their meal, presumably to reduce their immediate oxygen requirements. Then, as soon as water $\mathrm{So}_{2}$ was brought back above $45 \%$, approximately 5 min later, fish recovered enough metabolic potential to resume digestion and they re-swallowed all the food. This impact of reduced oxygen availability on fish feeding behavior was recently documented by Chabot and Dutil (1999). These authors measured food ingestion and growth in cod reared at $\mathrm{O}_{2}$ saturation levels ranging from 45 to $93 \%$. They showed that growth rate was directly related to oxygen availability and that $97 \%$ of the reduction in growth was explained by reduced food consumption. Based on equation 6 it can be hypothesised that the observed decrease in food ingestion represented a behavioural adaptation to the oxygen-mediated reduction in metabolic scope (Fig. 4).

The present study supports the view that energetics can be used as a tool to investigate fish distribution and behavior in nature (Magnuson et al., 1979). From this perspective, water temperature is certainly a powerful factor, influencing both fish distribution and behavior 
(Coutant, 1990; Magnuson and Destasio, 1996). This environmental influence has also been documented in Atlantic cod (D’Amours, 1993; Claireaux et al., 1995a; Brander, 1996). Fish species that inhabit the Canadian Scotian Shelf are typically faced with water temperatures ranging from 2 to $8{ }^{\circ} \mathrm{C}$ (Scott, 1982). Our model indicates that over such a temperature range, MS is increased by as much as $60 \%$, underlining the potent contribution of the thermal component in determining the actual niche of Atlantic cod. He (1991) showed that cod maximum sustained swimming speed at $0{ }^{\circ} \mathrm{C}$ was only $56 \%$ that at $5{ }^{\circ} \mathrm{C}$ and $46 \%$ that at 8 ${ }^{\circ} \mathrm{C}$. These results match the temperature related decrease in MS observed in the present investigation.

In its current form, our model predicts that cod metabolic scope is maximised in the temperature range of $13-15^{\circ} \mathrm{C}$. These values are outside of the experimental range considered in the current work, therefore, our model needs to be extended further. However, this is in line with the thermal preferendum range of $11-14{ }^{\circ} \mathrm{C}$ reported in the litterature for cod (Clark and Green, 1991; Schurmann and Steffensen, 1992).

Despite the strength of temperature as a directive force, cod and many other species of fish are found mostly at temperatures lower than their thermal preferendum. Magnuson and Destasio (1996) proposed 3 reasons for the fact that a fish may not occupy its fundamental thermal niche; 1) the niche is not available in the ecosystem it inhabits, 2) there are interactions between temperature and other abiotic and biotic niches, 3) there are intra and interspecitic competition for the same thermal resource. However, we can speculate that the coercive effect of temperature on metabolism can reciprocally create an efficient behavioral mechanism for cod to tune their energetic expenditure according to the environmental conditions encountered (e.g. hypoxia; Schurmann and Steffensen, 1994) or to its 
physiological state (e.g. fed/unfed; Sogard and Olla, 1996). In the range where metabolism displays the highest temperature-dependency $\left(\mathrm{Q}_{10}\right)$, the adaptative benefit of an accurate use of this two-edged thermal effect (i.e. controling/directive) should not be disregarded, particularly in the case of species living in non homogenous (temperate) environments. It is worth noting that the temperature range where $\frac{\partial M S}{\partial T}$ is maximal corresponds with the realized thermal niche of many temperate species, including the Scotian Shelf cod (Scott, 1982) and the Northeast Atlantic sea bass (Pickett and Pawson, 1994).

The preponderant influence of water temperature on the route swum by Atlantic cod during their yearly migration was illustrated nicely by Rose (1993). This author showed that the shoreward migration of cod across the cold $\left(0^{\circ} \mathrm{C}\right)$ Northeast Newfoundland Shelf could be predicted under the assumption that migratory routes follow trenches holding warmer oceanic waters $\left(2-3^{\circ} \mathrm{C}\right)$. Based on our model, it can be calculated that by following these warm-water corridors, migrating cod raised their power rating by as much as $60 \%$, presumably providing themselves with the supplementary metabolic potential necessary to perform activities such as locomotion, spawning, foraging or escape.

In conclusion, the present investigation provides some insights on the energetic interactions which govern the relationships between Atlantic cod and its environment. The powerful effect of the physical environment on scope for activity is particularly crucial if one considers that the magnitude of the metabolic potential is negatively related to mortality risk (Priede, 1977). Accordingly, when published experimental and field studies are re-examined from the angle of the regulation of metabolic power output, they suggests that, when faced with heterogeneous or unstable hydrological conditions, cod, like sea bass, do tend to behaviorally 
maximize their scope for activity. Through this adaptative response, these species are likely to reduce energy budgeting conflicts and presumably increase the probability of routinely operating away from lethal boundaries (Priede, 1985).

\section{Acknowledgments}

Authors are indebted to T. Bishop for skilled technical assistance. Financial support to GC and JPL by the French Ministry of Foreign Affairs and IFREMER is also gratefully acknowledged. 


\section{References}

Beamish, F.W.H., 1964. Respiration of fishes with special emphasis on standard oxygen consumption. III. Influence of weight and temperature on respiration of several species. Can. J. Zool., 42: 177-188.

Blaikie, H.B. and Kerr, S.R., 1996. Effect of activity level on apparent heat increment in Atlantic cod, Gadus morhua. Can. J. Fish. Aquat. Sci., 53: 2093-2099.

Boutilier, R.G., Hemming, T.A. and Iwama, G.K., 1984. Physico-chemical parameters for use in fish respirometry physiology. In Hoar, W.S. and Randall, D.J. (Eds), Fish Physiology, vol. X. Academic press, New York. 403-430.

Brander, K., 1996. Effects of climate change on cod (Gadus morhua) stocks. In Wood, C.M. and McDonald, D.G. (Eds), Global warming: implications for freshwater and marine fish. S.E.B. seminar series. Cambridge University Press, 255-278.

Bushnell, P.G., Steffensen, J.F., Schurmann, H. and Jones, D.R., 1994. exercise metabolism in two species of cod in arctic waters. Polar Biol., 14: 43-48.

Chabot, D. and Dutil, J.-D., 1999. Reduced growth of Altantic cod in non-lethal hypoxic conditions. J. Fish Biol., 55: 472-491.

Claireaux, G. and Lagardère, J.-P., 1999. Influence of temperature, oxygen and salinity on the metabolism of the european sea bass. J. Sea Res., 42: 157-168. 
Claireaux, G., Webber, D.M., Kerr, S.R. and Boutilier, R.G., 1995a. Physiology and behaviour of free swimming Atlantic cod, Gadus morhua, facing fluctuating temperature conditions. J. Exp. Biol., 198: 49-60.

Claireaux, G., Webber, D.M., Kerr, S.R. and Boutilier, R.G., 1995b. Physiology and behaviour of free swimming Atlantic cod, Gadus morhua, facing fluctuating salinity and oxygenation conditions. J. Exp. Biol., 198: 61-69.

Clark, D.S. and Green, J.M., 1991. Seasonal variatin in temperature preference of juvenile Atlantic cod (Gadus morhua) with evidence supporting an energetic basis for their diel vertical migration. Can. J. Zool., 69: 1302-1307.

Coutant, C.C., 1990. temperature-oxygen habitat for fresh water and coastal striped bass in a changing climate. Trans. Amer. Fish. Soc., 109: 195-202.

D’Amours, D., 1993. The distribution of cod (Gadus morhua) in relation to temperature and oxygen level in the Gulf of St Lawrence. Fish. Oceanogr., 2: 24-29.

Davis, J.C., 1975. Minimal dissolved oxygen requirements of aquatic fife with emphasis on canadian species: a review. J. Fish. Res. Board Can., 32: 2295-2332.

Dutil, J.D., Lambert, Y and Boucher, E., 1997. Does higher growth rate in Atlantic cod (Gadus morhua) at low salinity result from lower standard metabolic rate or increased protein digestibility ? Can. J. Fish. Aquat. Sci., 54 (Suppl. 1): 99-103. 
Edwards, R.R.C., Finlayson, D.M. and Steele, J.H., 1972. An experimental study of the oxygen consumption, growth, and metabolism of the cod (Gadus morhua L.). J. Exp. Mar. Biol. Ecol., 8: 299-309.

Evans, D.O., 1990. Metabolic thermal compensation by rainbow trout: Effect on standard metabolic rate and potential usable power. Trans. Amer. Fish. Soc., 119: 585-600.

Fry, F.E.J., 1971. The effect of environmental factors on the physiology of fish. In Hoar, W.S. and Randall, D.J. (Eds), Fish Physiology, vol. VI. Academic press, New-York, 1-98.

He, P., 1991. Swimming endurance of the Atlantic cod, Gadus morhua L., at low temperatures. Fish. Res., 12: 65-73.

Hop, H. and Graham, M., 1995. Respiration of juvenile Arctic cod (Boreogadus saida): effects of acclimation, temperature and food intake. Polar Biol., 15: 359-367.

Jobling, M. 1993. Bioenergetics: feed intake and energy partitioning. In Rankin, J.C. and Jensen, F.B. (Eds), Fish Ecophysiology. Chapman and Hall, London.

Kerr, S.R., 1990. The Fry paradigm: its significance for contemporary ecology. Trans. Amer. Fish. Soc., 119: 779-785.

Magnuson, J.J., Crowder, L.B. and Medrick, P.A., 1979. Temperature as an ecological resource. Am. Zool., 19: 331-334. 
Magnuson, J.J. and Destasio, B.T., 1996. Thermal niche of fishes and global warming. In Wood, C.M. and McDonald, D.G. (Eds), Global warming: implications for freshwater and marine fish. S.E.B. seminar series. Cambridge University Press.

Neill, W.H., Miller, J.M., Van Der Veer, H.K. and Winemiller, K.O., 1994. Ecophysiology of marine fish recruitment: A conceptual framework for understanding interannual variability. Neth. J. Sea Res., 32:135-152.

Nelson, J.A., Tang, Y. and Boutilier, R.G., 1994. Differences in exercise physiology between two Atlantic cod (Gadus morhua) populations from different environments. Physiol. Zool., 67: 330-354.

Nelson, J.A., Tang, Y. and Boutilier, R.G., 1996. The effects of salinity change on the exercise performance of two Atlantic cod (Gadus morhua) populations inhabiting different environments. J. Exp. Biol., 199: 1295-1309.

Pickett, G.D. and Pawson, M.G., 1994. Sea bass: biology, exploitation and conservation. Fish and Fisheries series. Chapman and Hall, London.

Priede, I.G., 1977. Natural selection for energetic efficiency and relationship between activity level and mortality. Nature, 267: 610-612.

Priede, I.G., 1985. Metabolic scope in fish. In Tyler, P. and Calow, P. (Eds), Fish energetics new perspectives. Croom Helm, London. 
Reidy, S.P., Nelson, J.A., Tang, Y. and Kerr, S.R., 1995. Post-exercise metabolic rate in Atlantic cod and its dependence upon the method of exhaustion. J. Fish Biol., 47: 377-386.

Rose, G.A., 1993. Cod spawning on a migration highway in the north-west Atlantic. Nature, 366: 458-461.

Rose, G.A., 1997. The trouble with fisheries science. Rev. Fish Biol. Fisheries, 7: 365-370.

Saunders, R.L., 1963. Respiration of the Atlantic cod. J. Fish. Res. Board Can., 20: 373-386.

Schurmann, H., Claireaux, G. and Chartois, H., 1998. Changes in vertical distribution of sea bass (Dicentrarchus labrax) during a hypoxic episode. In Lagardère, J.-P., Bégout Anras M.L. and Claireaux, G. (Eds), Advances in invertebrates and fish telemetry. Developments in hydrobiology series. Kluwer Academic Publisher, Dordrecht, Boston, London. 207-213.

Schurmann, H. and Steffensen, J.F., 1992. Lethal oxygen levels at different temperature and the preferred temperature during hypoxia on the Atlantic cod, Gadus morhua. J. Fish Biol., 41: 927-934.

Schurmann, H. and Steffensen, J.F., 1994. Spontaneous swimming activity of Atlantic cod, Gadus morhua exposed to graded hypoxia at three temperatures. J. Exp. Biol., 197: 129-142.

Schurmann, H. and Steffensen, J.F., 1997. Effects of temperature, hypoxia and activity on the metabolism of juvenile Atlantic cod. J. Fish Biol., 50: 1166-1180. 
Scott, J.S., 1982. Depth, temperature and salinity preferences of common fishes of the Scotian Shelf. J; Northw. Atl. Fish. Sci., 3: 29-39.

Soofiani, N.M. and Hawkins A.D., 1982. Energetic costs at different levels of feeding in juvenile cod, Gadus morhua. J. Fish Biol., 21: 577-592.

Soofiani, N.M. and Priede I.G., 1985. Aerobic metabolic scope and swimming performance in juvenile cod, Gadus morhua. J. Fish Biol., 26: 127-138.

Sogard, S.M. and Olla, B.L., 1996. Food deprivation affect vertical distribution and activity of a marine fish in a thermal gradient: potential energy-conserving mechanisms. Mar. Ecol. Prog. Ser., 133: 43-55.

Steffensen, J.F., Bushnell, P.G. and Schurmann, H., 1994. Oxygen consumption in four species of teleosts from Greenland: no evidence of metabolic cold adaptation. Polar Biol., 14: 49-54.

Tang, Y., Nelson, J.A., Reidy, S.P., Kerr, S.R. and Boutilier, R.G., 1994. A reappraisal of activity metabolism in Atlantic cod (Gadus morhua). J. Fish Biol., 44: 1-10.

Tomkiewicz, J., Lehmann, K.M. and St John, M.A., 1997. Oceanographic influences on the distribution of Baltic cod, Gadus morhua, during spawning in the Bornholm bassin of the Baltic Sea. Fish. Oceanogr., 7: 48-62. 
Webber, D.M., Boutilier, R.G. and Kerr, S.R. (1998). Cardiac output as a predictor of metabolic rate in cod (Gadus morhua). J. Exp. Biol., 201: 2779-2789. 
Table 1. Parameter values issued from the modelling of the LOC-curves (equation 1).

\begin{tabular}{rccc}
\hline & $\mathrm{Y}_{1}$ & $\alpha_{1}$ & $\beta_{1}$ \\
\hline $10^{\circ} \mathrm{C}$ & 177.2 & -0.035 & 0.33 \\
$5^{\circ} \mathrm{C}$ & 120.5 & -0.034 & 0.31 \\
$2^{\circ} \mathrm{C}$ & 64.9 & -0.035 & 0.37 \\
\hline
\end{tabular}



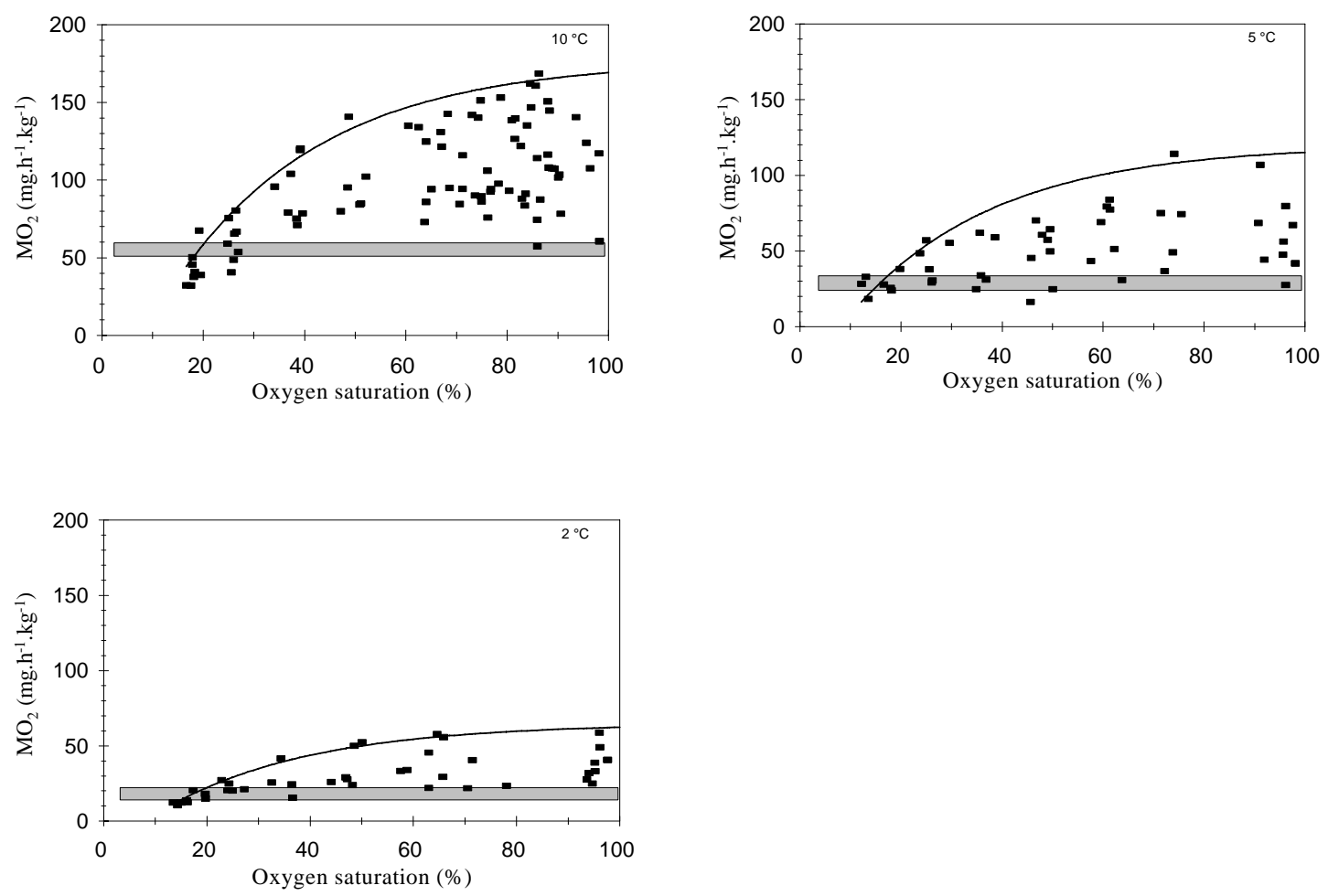

Figure 1. Effects of water temperature and oxygenation on the metabolism of Atlantic cod. Solid lines: relationships between $\mathrm{MO}_{2}$ max and water oxygenation (LOC-curves; equation 1). At each temperature, AMR is given by the asymptote of the corresponding LOC-curve. Shaded area: SMR \pm SE. The oxygen saturation where the LOC-curve crosses SMR corresponds to the critical oxygen saturation $\left(\mathrm{S}_{\text {crit }}\right)$. 


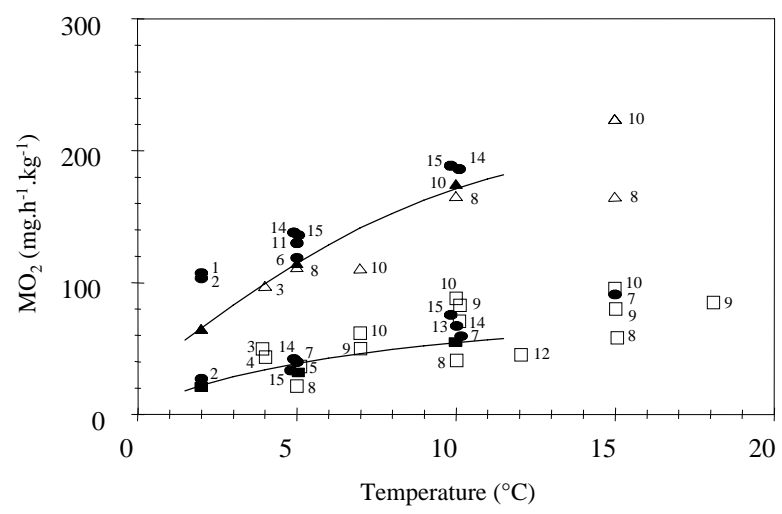

Figure 2. Relationships between AMR and temperature (closed triangles and the associated solid line; equation 8) and between SMR and temperature (closed squares and the associated solid line; equation 7). Open triangles published AMR. Open squares published SMR. (1) Nelson et al. (1994); (2) Nelson et al. (1995); (3) Bushnell et al. (1994); (4) Steffensen et al. (1994); (5) Claireaux et al. (1995a); (6) Reidy et al. (1995); (7) Saunders (1963); (8) Schurmann and Steffensen (1997); (9) Soofiani and Hawkins (1982); (10) Soofiani and Priede (1985); (11) Tang et al. (1994); (12) Edwards et al. (1972); (13) Blaikie and Kerr (1996); (14) Dutil et al. (1997); (15) Webber et al. (1998). 


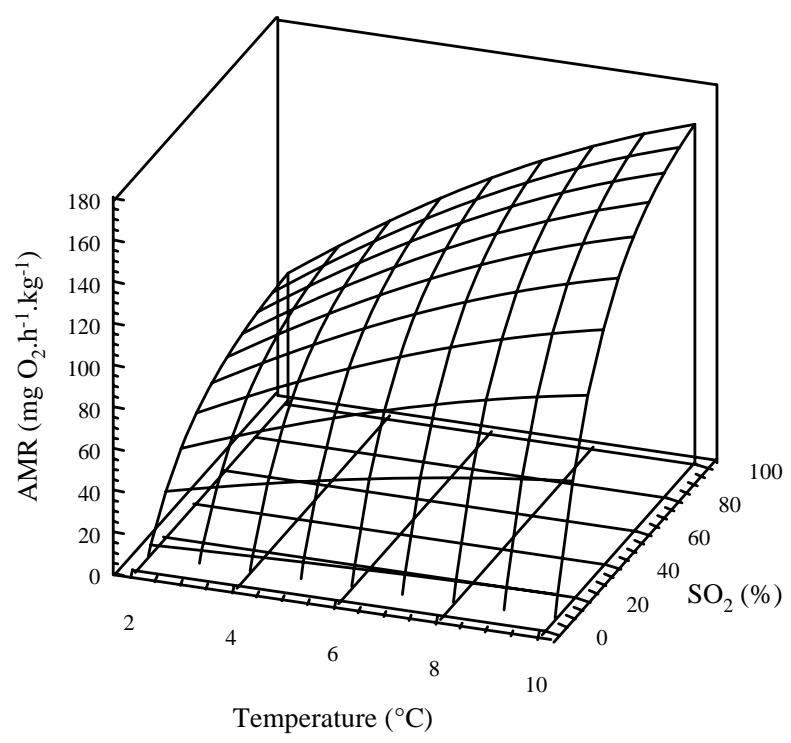

b

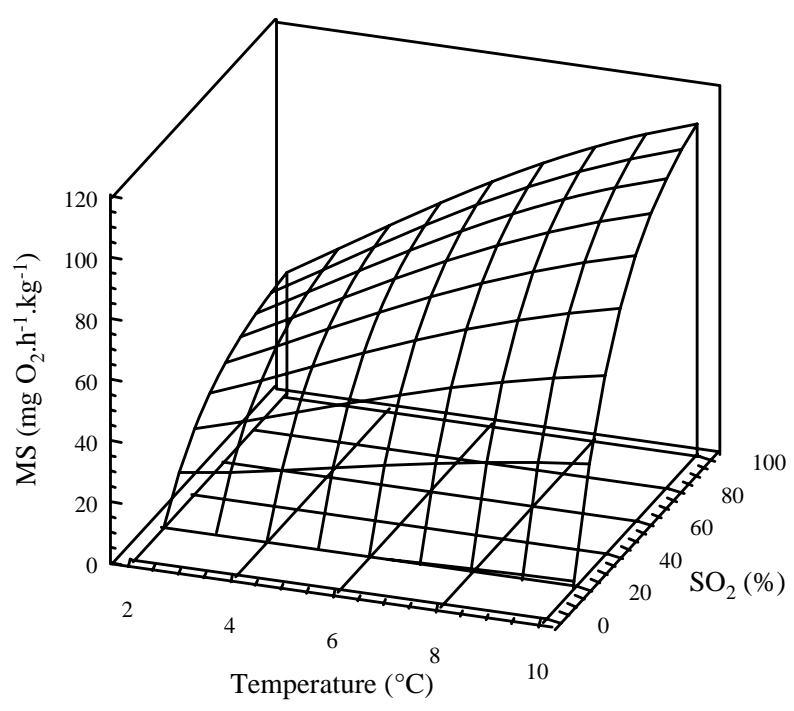

Figure 3. a- 3D representation of the relationship between maximum oxygen consumption $\left(\mathrm{MO}_{2} \mathrm{max}\right)$, temperature and oxygen (equation 9). b- 3D representation of the relationship between metabolic scope, temperature and oxygen (equation 10). 


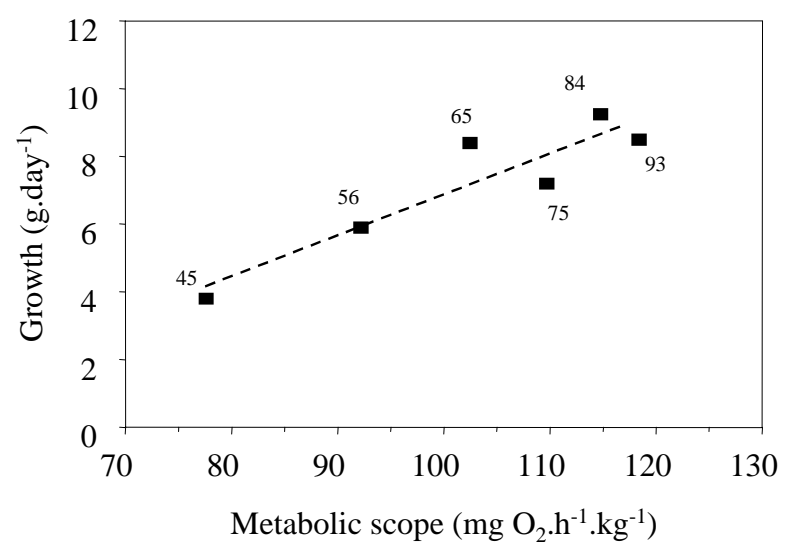

Figure 4. Relationship between growth rate and metabolic scope established based on equation 6 and using data from Chabot and Dutil $1999\left(y=0.124 x-5.597, r^{2}=0.85\right)$. Water temperature $10^{\circ} \mathrm{C}$. Numbers on the figure indicate ambient $\mathrm{O}_{2}$ saturation. 